\title{
EDUCACIÓN INTERCULTURAL BILINGÜE EN ARGENTINA: UN PANORAMA ACTUAL
}

Ana Carolina Hecht ${ }^{1}$

\section{Resumen}

El objetivo de este artículo fue analizar un estado de la cuestión sobre las políticas de Educación Intercultural Bilingüe (EIB) en Argentina. La EIB se refiere a las propuestas educativas cuya meta es atender las necesidades particulares de las minorías etnolingüísticas. En este texto, en un principio, se contextualizan históricamente a las políticas educativas para la diversidad cultural y lingüística; luego, se definen algunos rasgos que caracterizan a la EIB como política educativa; Por último, en las conclusiones, se exponen los desafíos a futuro de esta política educativa. Este texto contribuye al campo de los estudios sobre la diversidad en la escolarización de los diferentes grupos étnicos.

Palabras clave: Educación Intercultural Bilingüe, pueblos indígenas, Argentina, política educativa, diversidad, desigualdad.

\section{Summary}

The goal of this article is to assess the state of affairs of Intercultural Bilingual Education (IBE) policies in Argentina. IBE encompasses educational proposals designed to address the specific needs of ethnolinguistic minorities. In the first section of this paper, the educational policies on cultural and linguistic diversity are contextualized historically. Later, IBE is defined considering main characteristics of this education policy. Finally, the conclusions list the challenges, goals that have yet to be achieved and the future perspectives of this educational policy. This article contributes to the field of studies on diversity in the schooling of ethnically different groups.

Keywords: Intercultural Bilingual Education, Indigenous people, Argentina, Educational Policy, Diversity-Inequality.

1 Doctora por la Universidad de Buenos Aires con especialización en Antropología, docente de la Facultad de Filosofía y Letras de la Universidad de Buenos Aires, Argentina (UBA) e Investigadora del Consejo Nacional de Investigaciones Científicas y Técnicas (CONICET). Correo electrónico: anacarolinahecht@yahoo.com.ar 


\section{Introducción}

En América Latina desde hace décadas se debate acerca de los diferentes asuntos concernientes al tratamiento de la diversidad étnica y lingüística con el fin de promover relaciones equitativas e igualitarias entre distintos grupos socioculturales. Así, se intenta superar problemáticas afines a la discriminación y a la exclusión social, económica, cultural y política. En esos debates los modelos para la escolarización de las poblaciones indígenas han sido un foco central de discusión, contándose con experiencias sistematizadas como es el caso de Bolivia o México. No obstante, se trata de un asunto de disputa y reciente instauración en otros contextos, tal como sucede en Argentina.

La diversidad etnolingüística de los pueblos indígenas de Argentina históricamente se ocultó tras un imaginario asociado a una población oriunda de la migración europea. No obstante, a partir de algunos cambios políticos datados en las últimas tres décadas -como la llegada de la democracia y los nuevos paradigmas sobre la pluralidad cultural-, en el contexto nacional se vienen desarrollando proyectos educativos para incluir y atender las necesidades de las poblaciones originarias. De ese modo, surge la Educación Intercultural Bilingüe (EIB) teniendo como destinatarias a las minorías étnicas, quienes no sólo se encuentran interpeladas por su diversidad lingüístico-cultural, sino que además subsisten en entornos de extrema desigualdad y pobreza. En ese sentido, la EIB tiene un doble desafío: contemplar la pluralidad etnolingüística así como también considerar la vulnerabilidad socioeconómica de las poblaciones indígenas.

Con el objetivo de realizar un balance de la EIB en Argentina se analiza su definición, alcance y desafíos pendientes. Para ello, este artículo se organiza en tres apartados. Primero, se revisan someramente las características históricas que han tenido las políticas educativas para la alteridad en Argentina; luego, se sistematiza la definición de la EIB considerando cinco rasgos que implícita o explícitamente han ido configurando a esta política a partir de la legislación nacional. Por último, en las conclusiones se problematizan las perspectivas a futuro de esta política educativa.

\section{Revisión de literatura}

Argentina en la actualidad se define como un país pluriétnico y multilingüe, compuesto por veinte pueblos indígenas (pilagás, mocovíes, chiriguanos, chanés, tapietés, mbyá, wichís, mapuche, toba, kolla, nivaclés, guaraní, tupí-guaraní, diaguita/diaguita calchaquí, ava-guaraní, tehuelche, chorotes, rankulche, huarpe y ona) y donde, además del español y las lenguas de migración, se hablan catorce lenguas indígenas con diferentes grados de vitalidad. Según las estimaciones estadísticas del último censo poblacional (INDEC, 2010) se calcula que aproximadamente el $2 \%$ de la población 


\section{EDUCACIÓN}

se declara indígena o descendiente de algún pueblo originario ${ }^{2}$ y el $5 \%$ nacida en el extranjero (mayormente del resto de Latinoamérica y Europa, seguido de Asia y en menor medida África).

Frente a esta pluralidad, las planificaciones educativas para las minorías étnicas han tenido distintas características según los períodos históricos. En términos generales, se perciben dos tendencias: modelos escolares monolingües donde se marginan y niegan especificidades lingüístico-culturales bajo pautas hegemónicas y asimilacionistas (políticas homogeneizadoras), y modelos escolares bilingües insertos en programas compensatorios neoliberales donde se encubren las desigualdades socioeducativas (políticas focalizadas). Si bien se pueden encontrar entrecruzamientos y coexistencia de ambas tendencias en distintos períodos, se puede señalar que el primero es prototípico de la etapa del establecimiento del Estado Nacional (XIX y XX), mientras que el segundo se corresponden con la época contemporánea.

En artículos anteriores (Hecht 2007, 2009, 2010) se desarrollaron los vaivenes y las características que los diseños educativos homogeneizadores y focalizados han impregnado en las políticas tendientes a incluir a la diversidad sociocultural en la escuela. Más allá de estas cuestiones, interesa remarcar aquí el estigma de nacimiento que tienen las políticas de EIB en Argentina por surgir como políticas focalizadas en el contexto neoliberal.

Sin embargo, la EIB también debe comprenderse en el marco de las reformas legislativas post restitución democrática (1983) que reconocen derechos diferenciales para los pueblos indígenas. En relación con estas modificaciones se percibe que el discurso oficial atenúa su histórica mirada etnocéntrica para reconocer la pluralidad étnica y respetar las múltiples identidades. No obstante, cotidianamente se constata la ausencia de voluntad política para ejecutar la normativa en acciones de reconocimiento, aumentando el hiato entre el discurso y la práctica.

En el campo educativo, se cuenta con una amplia legislación nacional para el establecimiento de la EIB. ${ }^{3}$ Si bien hay sutiles particularidades en la definición de esta política, en la primera resolución se plasman los trazos más consensuados que la caracterizan:

“(...) es una educación atenta a la diversidad de culturas y lenguas de las poblaciones (...) Al mismo tiempo considera la relación de estas culturas y lenguas con las sociedades nacionales e internacionales en las que están insertas. (...) Esta educación

2 En Argentina los criterios censales para la identificación de los pueblos indígenas son el auto-reconocimiento de la pertenencia y/o la ascendencia por tener antepasados originarios.

3 Resolución $N^{\circ} 107$ del Consejo Federal de Cultura y Educación (1999), Resolución No 549 del Ministerio de Educación Ciencia y Tecnología de la República Argentina (2004), Ley de Educación Nacional No 26.206 (2006), Documento para la Modalidad de Educación Intercultural Bilingüe en el Sistema Educativo Nacional del Consejo Federal de Educación (2010) y Resolución No 105 del Consejo Federal de Cultura y Educación (2010). 
es intercultural en tanto reconoce el derecho que las poblaciones aborígenes tienen a recuperar, mantener y fortalecer su identidad, así como a conocer y relacionarse con otros pueblos y culturas coexistentes en los ámbitos local, regional, nacional e internacional. (...) Esta educación es bilingüe en tanto desarrolla la competencia comunicativa de los educandos, a nivel oral y escrito, en la lengua o lenguas utilizadas en el hogar y en la comunidad, junto con el aprendizaje de otras lenguas de mayor difusión y uso en los ámbitos nacional e internacional" (Resolución 107, Consejo Federal de Cultura y Educación: 5-6).

La EIB, en oposición a las políticas homogeneizadoras, se ha planteado como una política educativa que pugna por trascender los estereotipos que identifican la diversidad sociocultural con carencias (educativas, lingüísticas, culturales, cognitivas). Es decir, surge con la ilusión de que el lema "somos todos iguales" se reactualice en "somos todos diferentes". Como sostiene la antropóloga Dolores Juliano (1997: 29): "Así el camino va, desde el pedido de la igualdad, al reconocimiento de la diferencia". En ese sentido, es importante que las políticas y prácticas en favor de la igualdad no solapen ni anulen a la diversidad, así como también las políticas y prácticas pro diversidad tienen que evitar mantener y /o enmascarar la desigualdad. Ya que, como indica Gimeno Sacristán (2008), todas las desigualdades son diversidades, aunque no toda la diversidad supone desigualdad. Por ello, se debe estar atento a que bajo el paraguas de la diversificación, no se esté encubriendo el mantenimiento o la provocación de la desigualdad. Reiteramos: las políticas y prácticas a favor de la igualdad pueden anular la diversidad, las políticas y prácticas estimulantes de la diversidad quizás consigan mantener, enmascarar y fomentar algunas desigualdades (Ibíd. 2008).

No obstante, no logra revertir esa mirada en su diseño ya que cuando el Ministerio de Educación argentino funda en 2004 el Programa Nacional de EIB lo delega bajo la supervisión de la Dirección Nacional de Programas Compensatorios, dependiente de la Subsecretaria de Equidad y Calidad. Así, se atenta contra la idea de que el enfoque intercultural es transversal al sistema escolar y sigue vigente presuponer que la diferencia cultural es un "problema" o "carencia" a subsanar con políticas educativas compensatorias. Aunque, se debe hacer una salvedad porque en 2007 el área de EIB pasó a la Dirección Nacional de Gestión Curricular y Formación Docente del Ministerio de Educación. Resulta auspiciosa esta reubicación en el organigrama institucional porque supera la equiparación diversidad-diferencia-desventaja, si bien hasta la actualidad no hay datos que ratifiquen lo promisorio del cambio.

En ocasiones se pierde de vista que la EIB es un campo de derechos luchados y ganados por las comunidades y organizaciones indígenas, hecho que nos obliga a estar alerta frente a la despolitización del discurso dado que no se habla más de desigualdad social sino de diversidad cultural, bajo el supuesto erróneo de que la desigualdad no 
puede eliminarse pero las diferencias pueden articularse armónicamente (Alonso y Díaz, 2004).

Por todo lo antedicho, y más allá del giro novedoso que esta propuesta instaura en comparación con la tradicional educación homogeneizadora, retomamos el cuestionamiento (Ibíd. 2004) al presupuesto ingenuo de que la educación intercultural implica por sí misma una modificación del statu quo. Es imprescindible debatir sobre el "para qué" y "desde dónde" de una educación en contextos de diversidad/desigualdad, ya que la EIB no es una simple "pedagogización" del discurso y la práctica intercultural (Dietz, 2012), sino que trata de relaciones entre sujetos político-culturales insertos en tramas jerárquicas de poder. También autoras como Paladino y Czarny (2012) señalan que la interculturalidad como política educativa en los países de la región latinoamericana ha funcionado como un instrumento de empoderamiento de los sectores subalternos, pero para otros es una herramienta que solapa la desigualdad detrás de un énfasis en las diferencias. Es decir, Paladino y Czarny (2012) desenmascaran cómo la interculturalidad como concepto se asocia tanto a la construcción de proyectos sociales, políticos y epistemológicos alternativos y orientados a la descolonización, así como también a un dispositivo que disciplina las diferencias sin subvertir las relaciones de poder y desigualdad.

Tal como se documentó en otros artículos (Hecht 2007 y 2009 y Borton et al. 2010), las características que los modelos homogenizados y focalizados impregnan en los diseños educativos son múltiples, complejas y tal vez involuntarias. Por ello, pareciera existir cierto falso dilema dicotómico entre una inclusión asimilacionista y una exclusión segregadora (Borton et al, 2010). O sea, entre un esfuerzo de inclusión de la diversidad que termina siendo asimilacionista y un rescate de la diversidad que al folklorizarla y estancarla genera segregación. Desde caminos distintos, los efectos de ambas iniciativas terminan asemejándose porque ninguno de los polos termina por desestabilizar al curriculum hegemónico (Connell, 1997). En el primer caso, se incluye a los alumnos en un currículo común dominante; en el segundo se elabora un currículum que si bien atiende las particularidades e intereses locales, termina cerrándose sobre sí mismo. Ambas iniciativas distan de resultar efectivamente democratizantes $y$, aunque embanderadas de buenas intenciones, profundizan la desigualdad que intentan combatir. En consecuencia, existen brechas enormes entre los fines que dan origen a la EIB y las formas concretas adoptadas institucionalmente.

\section{Resultados y discusión}

Las investigaciones latinoamericanas sobre Educación Intercultural Bilingüe se han focalizado en distintas tendencias en las últimas dos décadas. Por un lado, se incrementan las publicaciones que alertan sobre los procesos de sustitución y pérdida de las lenguas indígenas americanas en favor de otras lenguas más poderosas en los contextos políticos y económicos actuales. Por otro lado, aún son cuestionados 
los beneficios y posibilidades educativas a las que han accedido los niños y jóvenes indígenas en estos años, así como la calidad educativa de las propuestas educativas bilingües e interculturales. También han proliferado los debates acerca las implicancias que acarrearían diseños proclives a posicionarse desde enfoques descolonizadores de la educación en América Latina. Como sostiene Dietz (2012) en las discusiones contemporáneas sobre EIB se carece de una definición común de lo que supone una educación multi/intercultural, los debates se circunscriben sólo al ámbito escolar desvinculando al contexto social que origina esos escenarios y son generalizados los solapamientos entre el nivel analítico y el normativo.

En el caso de Argentina se trata de un tema en incipiente expansión como campo de debate teórico. La mayoría de los artículos sobre cuestiones de la EIB refieren a relatos de experiencias escolares específicas. Sin embargo, en este texto me propongo efectuar una sistematización más global que posibilite que distintos lectores de la región latinoamericana puedan tener un panorama actual que alcance a definir como se entiende a la EIB en Argentina. Para ello, a partir de lo afirmado en la legislación argentina, la bibliografía pertinente y mi experiencia de investigación ${ }^{4}$, se procurará sistematizar algunas características centrales que delinean a la EIB en el contexto nacional.

La EIB se traduce en las aulas escolares argentinas de la siguiente forma: se trata de escuelas destinadas a población indígena y cuentan con dos maestros, el maestro indígena y el maestro no-indígena. Al primero -más allá de los diferentes nombres que recibe en cada provincia: Auxiliar Docente Aborigen y Profesor Intercultural Bilingüe (Chaco), Maestro Especial para la Modalidad Aborigen (Formosa), Auxiliar Bilingüe (Salta), etc.- corresponde la enseñanza de la lengua indígena y los denominados "contenidos culturales", mientras que al segundo la enseñanza del español y el resto de las asignaturas (matemática, ciencias sociales, ciencias naturales, etc.). En la EIB coexisten estos dos maestros, pero cabe decir que la convivencia es muy compleja, con múltiples tensiones a nivel personal y profesional, por razones como el tipo de formación recibida, los contenidos que tiene cada uno a cargo y jerarquías implícitas entre ambos.

Pero vayamos en detalle recorriendo esta caracterización más general de la EIB. Puntualmente, la Ley de Educación Nacional ( $\mathrm{N}^{\circ}$ 26.206/2006) define a la EIB como una modalidad educativa ${ }^{5}$ :

La modalidad del sistema educativo de los niveles de Educación Inicial, Primaria y Secundaria que garantiza el derecho constitucional de los pueblos indígenas, conforme

4 Me refiero a investigaciones etnográficas y de gestión/intervención efectuadas desde 2001 hasta el presente en el campo de la antropología lingüística y educativa con comunidades wichís y chorotes (Salta), wichís (Formosa) y tobas (Buenos Aires y Chaco).

5 La estructura del sistema educativo argentino comprende cuatro niveles (inicial, primario, secundario y superior) en ocho modalidades (EIB, Educación Técnico Profesional, Educación Artística, Educación Especial, Educación Permanente de Jóvenes y Adultos, Educación Rural, Educación en Contextos de Privación de Libertad, Educación Domiciliaria y Hospitalaria). 
al Artículo 75, inciso 17 de la Constitución Nacional, a recibir una educación que contribuya a preservar y fortalecer sus pautas culturales, su lengua, su cosmovisión e identidad étnica; a desempeñarse activamente en un mundo multicultural y a mejorar su calidad de vida. Asimismo, la Educación Intercultural Bilingüe promueve un diálogo mutuamente enriquecedor de conocimientos y valores entre los pueblos indígenas y poblaciones étnica, lingüística y culturalmente diferentes, y propicia el reconocimiento y el respeto hacia tales diferencias (Ley de Educación Nacional, Capítulo XI, Artículo 52).

Esta definición reduce la EIB a los pueblos indígenas y en los tres primeros niveles educativos. Si bien la propuesta de modalidades parece superar la visión guettizadora y compensatoria de la educación -en tanto se entiende como un proyecto que responde y atiende requerimientos específicos con el propósito de garantizar la igualdad en el derecho a la educación-, aún se tienen dudas al respecto por su estrecho foco de alcance. La reducción de los destinatarios de la EIB "sólo para indígenas", hace perder de vista la transversalidad que debieran tener estas propuestas y excluye a los estudiantes migrantes y no-indígenas. Esta equiparación (interculturalidad igual indígenas) en el contexto argentino es muy compleja por varias razones. Por un lado, por el isomorfismo que suele asociar área indígena con zonas rurales, instaurando al espacio urbano como invisibilizador de la alteridad, siendo que las regiones urbanas (como la ciudad y los alrededores de Buenos Aires) son las que concentran mayor proporción de pueblos indígenas. Por otro lado, porque además de población indígena hay numerosos migrantes que no son visibilizados y, en consecuencia, se producen formas sutiles de discriminación en el marco de una política que se propone inclusiva.

Otro rasgo llamativo que se deduce tanto de esta definición de EIB como de las experiencias documentadas, es la preocupación central por los niveles inferiores de la escolarización (inicial y primeros dos años de primario). A modo de ejemplo, según el último Relevamiento Anual (2009) efectuado por la Red Federal de Información Educativa, se constatan 424 unidades educativas de nivel inicial en modalidad de EIB, 720 en primario y 220 en nivel medio. Notoriamente se percibe el desinterés por los niveles más altos, inclusive negando al superior. El corolario de esta discontinuidad de la EIB en las trayectorias escolares de los destinatarios es la desvalorización de su patrimonio lingüístico-cultural en el largo plazo, y sin lograr trascender los modelos bilingües de transición.

Pero la cuestión de las lenguas en contacto en el marco de la EIB, amerita una reflexión en sí misma. La EIB propone acciones para incluir a las lenguas indígenas en los procesos de escolarización de los niños que se reconocen como pertenecientes a pueblos originarios. No obstante, no hay menciones explícitas sobre cómo incluir a las distintas lenguas en las aulas. Retomando a López (1988) entendemos que la política lingüística está en íntima asociación con la planificación educativa ya que a través 
de ésta se expresan los supuestos sobre cómo parece factible modificar, prescribir y jerarquizar las relaciones asimétricas entre las lenguas que coexisten en un Estado. Por lo tanto, este vacío en cuanto a la gestión de la diversidad lingüística no puede minimizarse y resulta sorprendente dado el plurilingüismo de Argentina: español como lengua oficial, lenguas indígenas y lenguas de migración tanto de origen indoeuropeo como indígena. En efecto, en los lineamientos oficiales se carece de una definición clara respecto de si la lengua de instrucción debe ser la lengua indígena, o si deben aplicarse modelos de enseñanza de español como lengua segunda, o si la alfabetización debe ser bilingüe o multilingüe o si las lenguas indígenas son las segundas lenguas.

Si bien la EIB no sienta una propuesta clara para atender la pluralidad sociolingüística, evidenciamos, más por omisión que por explicitación, un ideal: niños de comunidades indígenas rurales hablantes monolingües de una lengua indígena que toman por primera vez contacto con el español en la escuela. No obstante, cabe citar que según la Encuesta Complementaria de Pueblos Indígenas de Argentina (INDEC, 2004/2005) el 73\% de los indígenas afirma no hablar ni entender ninguna lengua indígena, frente a un $20 \%$ que tiene esas competencias y un $7 \%$ que no habla pero entiende alguna lengua nativa.

Pese estos datos sobre competencias lingüísticas en lenguas originarias, en la legislación sólo se encuentra una única mención sobre el desplazamiento lingüístico: "[la educación] puede ser considerada como bilingüe cuando en casos de retracción lingüística, existe una voluntad consciente de recuperación de la lengua" (Resolución $\mathrm{N}^{\circ}$ 549, 2004, Ministerio de Educación, Ciencia y Tecnología). Es decir, el requisito previo a la intervención es la necesidad de una voluntad consciente de recuperación lingüística. Sin embargo, esa mirada está desconociendo los procesos hegemónicos de dominación y estigmatización que median entre una "voluntad consciente" y las valoraciones o connotaciones negativas que subyacen al uso de lenguas minoritarias. Estas lenguas han atravesado procesos históricos de sometimiento y represión bajo las políticas homogeneizadoras y, además, actualmente pierden espacios de uso en tanto se asocian al "atraso", "discriminación" y "pobreza". Por lo tanto es casi imposible delimitar esa supuesta "voluntad consciente".

En resumen, negar la complejidad sociolingüística conlleva que muchos de los niños destinatarios de la EIB sean expulsados del sistema escolar público con argumentos que le endilgan la culpa a una supuesta "deficiencia cognitiva" cuando en realidad las causas pueden correlacionarse con la invisibilidad de las diversas situaciones sociolingüísticas. Justamente, el hecho de que las jurisdicciones donde se hablan lenguas aborígenes y variedades dialectales del español en contacto con lenguas indígenas duplican, y hasta triplican, las cifras nacionales de analfabetismo y repitencia (Acuña y Sierra, 2002) puede considerarse como un epifenómeno de esa negación de la diversidad sociolingüística. 


\section{Conclusiones}

Una vez presentado este balance de la EIB en Argentina, afloran muchos interrogantes al respecto. En primer lugar, parece imprescindible que se redefinan los límites en la extensión de esta política considerando distintas dimensiones: desde los destinatarios, lo geográfico y los niveles del sistema educativo. Desde los destinatarios, para contemplar a toda la sociedad y no sólo a aquellos marcados étnicamente como posibles focos de una educación intercultural; desde lo geográfico, para incluir a las poblaciones indígenas (y migrantes) que habitan en contextos urbanos desarticulando estereotipos y esencializaciones que asimilan alteridad con ruralidad; y desde los diferentes niveles del sistema educativo, para entender que la EIB no es sólo una cuestión pedagógica de los primeros años de inclusión en la escuela sino de trayectorias escolares.

Este somero análisis, como otros textos previos (Diez y Hecht, 2013) nos han servido para mostrar los notables límites en la extensión de esta política considerando, por ejemplo, la construcción de la interculturalidad en términos de cierta equivalencia con los pueblos indígenas, aunque con muchas limitaciones en la concepción de qué implica "lo indígena", tal como se ejemplifico en el recorrido sobre la inclusión de la diversidad lingüística en el marco escolar. Por ende, evidenciamos como las poblaciones migrantes no son vistas como potenciales destinatarias. Los niños inmigrantes, así como tantos otros niños de sectores populares, siguen siendo señalados por sus marcas culturales para dar cuenta de los dilemas que el profesorado enfrenta, pero poco visibles en el diseño de las políticas. Se desconocen sus saberes previos, trayectorias y experiencias formativas, haciéndolos invisibles para las políticas de EIB. Por lo tanto, aún son muchos los baches que debe zanjar la EIB para instalarse como una política atenta a la diversidad/desigualdad.

La EIB no debe comprenderse como un fin en sí mismo, sino un medio para producir cambios en la sociedad (Acuña 2005 y Dietz 2012). Al respecto, coincidimos con Alonso y Díaz (2004) en que la EIB no se hace sólo antropologizando los contenidos curriculares (cultura, diferencia, alteridad se vuelven vocablos de uso corriente), volviendo constructivistas los modos de transmisión y cambiando las actitudes intolerables por otras de respeto por la otredad. No sólo hay que pensar el qué y el cómo se educa, sino el para qué y desde dónde de la EIB en el contexto contemporáneo. En otras palabras, hay que politizar el discurso intercultural, y considerar que no es sólo un problema educativo sino que es social y político.

De este modo, parece importante partir de una mirada que descolonice la EIB y reflexione sobre las relaciones de subalternidad por fuera de la escuela. En otras palabras, la EIB tiene que ser reconocida como un campo de derechos luchados y ganados por colectivos indígenas, dejando de proceder como si la escuela estuviera aislada del contexto histórico y sociocultural, omitiendo la inferiorización y subordinación que padecen los pueblos indígenas no sólo en Argentina sino en toda América Latina. 


\section{Lista de referencia}

Acuña, L. (2005) Los chicos mismos te enseñan: bilingüismo en la educación intercultural bilingüe. Tissera de Molina, A. y J. Zigarán (comp.) Lenguas, educación y culturas. Salta: CEPIHA y Departamento de Lenguas Modernas, Universidad Nacional de Salta, pp. 21-44.

Acuña, L. y M. C. Sierra. (2002) Educación intercultural bilingüe en el departamento Ramón Lista (provincia de Formosa): comparación de propuestas y situación actual. Menéndez, Salvio; Adriana Cortés; Andrea Menegotto y Amalia Cócora (Eds.) Las teorías lingüísticas frente al nuevo siglo. Actas del VIII Congreso de la Sociedad Argentina de Lingüística. Mar del Plata: Edición en CD por la Sociedad Argentina de Lingüística.

Alonso, G. y R. Díaz. (2004) ¿Es la educación intercultural una modificación del statu quo? Díaz, Raúl y Graciela Alonso (Comp.) Construcción de espacios interculturales. Buenos Aires: Editorial Miño y Dávila, pp.75-96.

Borton, A., N. Enriz, M. García Palacios y A. C. Hecht (2010) Capítulo 8. Una aproximación a las representaciones escolares sobre el niño indígena como sujeto de aprendizaje. Silvia Hirsch y Adriana Serrudo (comps.) La Educación Intercultural Bilingüe en Argentina. Identidades, lenguas y protagonistas. Buenos Aires: Novedades Educativas, pp. 197- 222.

Connell, R. (1993) Escuelas y justicia social. Madrid: Ediciones Morata.

Consejo Federal de Cultura y Educación (1999). Resolución 107. Ministerio de Cultura y Educación Educación, Argentina.

Dietz, G. (2012) Multiculturalismo, interculturalidad y diversidad en educación. Una aproximación antropológica. México DF, México: Fondo de Cultura.

Diez, M. L. y Hecht, A.C. (2013) Interculturalidad en educación: discusiones y desafíos. XIV Jornadas y Primer Congreso Latinoamericano de Enseñanza de Lenguas Extranjeras en el Nivel Superior (XIV JELENS - I CLELENS), 23, 24 y 25 Octubre 2013. Universidad Nacional de La Pampa.

Gimeno Sacristán, J. (2008) La construcción del discurso acerca de la diversidad y sus prácticas. En: AAVV. Atención a la diversidad. Barcelona: Editorial Laboratorio Educativo y Graó. 
Hecht, A. C. (2007) Educación intercultural bilingüe: de las políticas homogeneizadoras a las políticas focalizadas en la educación indígena argentina. Revista Interamericana de Educación de Adultos 29, 1, 65-85.

Instituto Nacional de Estadísticas y Censos (INDEC) (2010). Censo Nacional de Población. Buenos Aires, Argentina.

------- (2009) Desplazamiento de lenguas y educación intercultural bilingüe. Un contrapunto entre políticas educativas y prácticas e ideologías lingüísticas de familias indígenas urbanas. En: Melgarejo, Patricia (comp.) Educación Intercultural en América latina. Memorias, horizontes históricos y disyuntivas politicas. México: Universidad Pedagógica Nacional, Consejo Nacional de Ciencia y Tecnología y Plaza y Valdés Editores, 175-199.

(2010) "Todavía no se hallaron hablar en idioma" Procesos de socialización lingüistica de los niños en el barrio toba de Derqui, Argentina. LINCOM Studies in Sociolinguistics 09, München, Lincom Europa, academic publications.

Juliano, D. (1997) Universal/Particular, un falso dilema. Globalización e identidad cultural. Ediciones Ciccus, Buenos Aires.

López, L. E. (1988) Lengua. Santiago de Chile: UNESCO-OREALC.

Ministerio de Educación. (2006) Ley de Educación Nacional. Argentina.

Paladino, M. y G. Czarny (orgs.) (2012) Povos indígenas e escolarização. Discussões para se repensar novas epistemes nas sociedades latino-americanas. Rio de Janeiro: Garamond.

Red Federal de Información Educativa. (2009) Relevamiento Anual. Ministerio De Educación Argentina. 